\title{
Muito além da Tevê Globo
}

Antonio Hohlfeldt Professor FAMECOS/ PUCRS Doutorando em Letras/ PUCRS
No DIA 10 de março de 1993, em Londres, divulgava-sepela primeiravez no exterior, as imagens deum documentário produzido por Simon Hartog intitulado Brasil: Beyond Citizen Kane. Poucos dias depois, o Museu da Imagemedo Som deSão Paulo, graças a uma cópia pirata obtida diretamente em Londres por uma telespectadora, fazia uma dupla apresentação do documentário, programando-se novas projeções para os dias 3 e 4 de junho. Contudo, na noite do dia 2, um tel efonema do Secretário de Cultura do Estado de São Paulo, Ricardo Ohtake, dirigido ao programador do MIS, jornalista Geraldo A nhaia Mello, cancelava aquelas apresentações. Formava-se, imediatamente, uma espécie de cadeia pirata em todo o país - novas cópias do vídeo foram produzidas edistribuídas Brasil afora, e alguns dos principais sindicatos começaram a programar a exibição do documentário. As versões sobre a proibição variam: Ohtake garante que não havia porque proibir, a não ser pelo fato desetratar de uma fita pirata. Anhaia, ao contrário, acusa diretamente a intervenção de Roberto Marinho, a subserviência do governador de São Paulo deentão edo seu Secretário deCultura. Há consenso, porém, numa coisa: não fora esseepisódio etalvez ofilme- queno exterior provocava batalha jurídica de mais de um ano da Globo contra o Canal 4 da BBC, tendo a Globo perdido a causa - não setornassetão conhecido, tão debatido, tão comentado quanto foi então. O processo se completa agora: a editora Scritta acaba de publicar a transcrição do roteiro do documentário, ilustrado por algumas de suas imagens. A edição traz um depoimento do próprio Geraldo Anhaia de Mello, responsável pela mesma. Do ponto devista brasileiro, éo mais recente, e felizmente já rel ativamente antigo episódio de tentativa de censura em nosso país. É claro, contudo, quea questão vai mais além do queisso, porqueenvolvea discussão em torno da própria política nacional de comunicações e, muito especialmente, os 
critérios pel os quais se concedem, mantém e renovam as concessões de canais de rádio e, sobretudo, de televisão.

O título - M uito A lém do Cidadão Kane - tal como se traduziu o livro que agora se lança, faz alusão direta à personagem criada por Orson Welles, em seu famoso filme, por seu lado referência direta ao magnata das comunicações dos Estados Unidos, William Randolph Hearst, cuja filha, décadas depois, envolver-se-ia com a guerrilha urbana. $\mathrm{Na}$ época, Hearst constituía-se em verdadeiro mito, e o filme de Welles tornou-se uma das dez obras-primas cinematográficas. Beyond Citizen Kane tem sido normalmente divulgado como sendo o documentário em torno da Televisão Globo e de seu multipoderoso proprietário, Roberto Marinho. Na verdade, a primeira observação que se deve fazer a respeitoéquesuaatenção seencontracentrada em Marinho enaTV Globo apenasporqueela é a exemplificação mais cabal e radical da experiência da política de telecomunicações brasileira. Simon Hartog, porém, queria ir mais longe, edefato foi, como o reconhece 0 próprio Anhaia: o que se pretende é denunciar a maneira palaciana pela qual Marinho ou Bloch, Sílvio Santos ou Saad, cada um pegou a sua fatia. M ais queisso, ecertamente os livros que se têm lançado recentemente sobre Samuel Wainer eA ssis Chateaubriand bem o evidenciam, Marinho não agiu diferentemente de como agiria qualquer um dos outros dois. A contecequeM arinho foi menos amador que os demais ou, quem sabe, o sistema capitalista no qual se acha hoje inserido o Brasil é mais ć́nico e eficiente do que aquele, ainda primário, experimentado pelas duas outras personagens. Portanto, 0 que se deve ter claro, desde logo, é que Marinho não é nem pior nem melhor que Wainer, Chateaubriand, Saad, Bloch ou qualquer outro. Foi, apenas, mais competente e eficiente, alcançando melhores resultados em suas manobras. $O$ episódio que culmina no papel da Globo em nossa realidade, contudo, tem de ser compreendido em sua perspectiva macro, ou seja, enquanto superestrutura social, política e econômica queviabilizataissituações, envolvendodesde aingenuidadedealguns segmentossindicais e de ativistas de esquerda, que imaginaram democratizar a política de concessões de canais de rádio e tel evisão quando retiraram a decisão exclusiva do Presidente da República, repartindo-a pelo Congresso Nacional, atéos profissionais jornal istasque, a exemplo de A rmando N ogueira ou Vianey Pinheiro, só contam as verdades depois que foram despedidos da emissora. Em última instância, é todo o conjunto da sociedade nacional que, de fato, responde por essa situação, na medida em que, conivente, dá à Globo aquilo que ela mais quer: a audiência quelhegaranteo poder da influência enegociação junto ao segmento político e administrativo.

Lembremo-nos que, paral elo ao controle censorial dos meios de comunicação, a ditadura brasileira de 1964, a partir do Ato Institucional no 5, em 1968, idealizou uma espécie de movimento compensatório positivo: tratava-se de atender à demanda do segmento da classemédia brasileiraque, embora nemtão numeroso assim, emtermosrelativos da população nacional, era suficientemente significativo para a indústria de bens duráveisqueentãocompensavaseinstalar no país, cobrindo de quinze a vinte milhões de pessoas e sendo superado, portanto, apenas por algunsraros outrosmercados, dentreosquais o norte-americano. Dequal quer maneira, justificava-se plenamentequalquer investimento, o que, aliás, éa única explicação para que se compreenda os fenômenos que ameaçam permanentemente o Plano Real, a chamada "bolha de consumo".

Havia, pois, um duplo movimento - de um lado, o controle censorial e, de outro, a cooptação mediante a ampliação das ofertas no mercado de consumo, ofertas essas viabilizadas, em sua divulgação, através de um network tal como a Globo o construiu ao longo dos anos. A Globo estreou no dia 26 de abril de 1965. Na verdade, fora antecedida pelo sinal pioneiro da TV Tupi, em 1950, seguida pela TV Excelsior em 1960. Duas emissoras e dois projetos absolutamente di- 
versos: a Tupi sucumbiria, em 1980, à queda do próprio império dos Diários Associados. A Excelsior enfrentaria problemas no futuro, não tendo sua concessão renovada, por ter tido a ousadia de resistir à ditadura. Transferida, numa espécie de leilão, para o grupo Bloch eSílvio Santos, abriria caminho para a TV Manchete e o SBT.

Iniciando-secom um empréstimo duvidoso medianteumaindamaisduvidosoacordo operacional como grupo norte-americano Time-Life, o queera proibido pela legislação brasileira, a TV Globo aproveitaria, suspeitamente, dois episódios, na aparência negativos, para seu crescimento, para firmarse e crescer: o primeiro foi, justamente, a decisão do Congresso N acional em dissolver o acordo da Globo com a Time-Life. Roberto Marinho não reclamou. Pelo contrário. É provável que os norte-americanos, sim, tenham acabado lesados no episódio, mas como sabiam perfeitamente os riscos que corriam, não chiaram.

O outro episódio ocorre em 1969: um incêndio destrói as instalações da Globo em São Paulo. A emissora centraliza o telejornalismo e toda a produção no Rio de Janeiro, graças ao dinheiro obtido pelo seguro, e assim garante a ocupação da magnífica sede do Jardim Botânico. De onde se depreende que Roberto Marinho é, acima de tudo, um excelente empresário e se, num primeiro momento, teveo máximo empenho em dar suporte e manter-se próximo ao segmento que identificava o governo ditatotial, na verdade seu interesse ia bem mais longe: "a Globo não tem uma vocação necessariamentemilitarista, ou ditatorial, mas ela tem uma vocação governista. Onde tem governo está a Rede Globo" - afirma o documentário, e pode-se verificar que, evidentemente, em sendo necessário el eger o governo, como no episódio Collor de Mello, ou apoiar sua derrubada, desde que isso signifiquea garantia deseus investimentose interessesfinanceiros, aempresanão titubeia. Claro, contando com cinco estações retransmissoras afiliadas, cobrindo $99,2 \%$ do território brasileiro ou 99,9\% dos aparelhos detelevisão do país, garantindo uma fatia de $78 \%$ da audiência, abocanhando 70 a $75 \%$ do total da mídia nacional que, no Brasil, naárea de tel evisão, ultrapassa os 50\%, ou seja, mais de dois bilhões de dólares em 1990, a Globo não pode titubear sobre a política de seu interesse.

Se ao governo federal a TV Globo interessa exatamente pelos fanáticos percentuais deaudiênciaqueatinge, garantia de que a mensagem governamental chegará ao seu destino, à Globo essa audiência Ihe dá um poder de barganha inigualável, transformando-a, literalmente, numa espécie de poder paralelo, maior que um simples quarto poder como se tem conhecido a mídia em geral. N ão setrata, porém, da aplicação pura esimples da vel ha fórmula da teoria do projétil, mecanicista. Dito mais claramente, não é apenas a questão de que a Globo diga o quê devemos pensar ou sonhar. Mais grave é o poder de agenda, na acepção do professor Donald McCombs, que torna hoje a Globo al tamente perigosa. A Globo diz sobre o quê devemos pensar, quais são os temas que de vem ou não ocupar nossas preocupações, tendo institucional izado, para tanto, um discurso tautológico que, estribado na qualidade - "padrão Globo"- na verdade vende sua própria imagem, reforçando-a permanentemente. É o caso típico de programas como Globo Repórter ou Fantástico, as promoções sociais de apelo humanitário que assina, a construção cuidadosa de uma auto-imagem em quea credibilidadeé o apelo mais veiculado, mesmo que muitas vezes seja posto em dúvidapor outrossegmentos sociais. O slogan "Globo e você, tudo a ver" como que institucionaliza a common view, um modo comum devisualizar arealidade, detal forma que a audiência alcançada, e amplamente divulgada, como que tautologicamente se mescla com o conceito de credibilidade: é como se pudesse garantir que a Globo tem audiência porque tem credibilidade. Assim, mais do que um quarto poder, a Globo se torna um Poder Oculto Supra-Real quesubstitui outras instâncias das relações sociais, mediante a constante reelaboração daquilo 
que Muniz Sodré já denominou de “simulacro", uma super-realidade que distancia de tal forma a realidade original, que simplesmente a retira de qualquer outra referencialidade: ainda que al guém estivesse vendo um certo fato acontecer, só acreditaria nele à medida em que isso fosse enfocado pelas imagens da televisão.

O mais grave, contudo, é que hoje a própria Televisão Globo começa a se tornar um meio para algo além de si mesma. São maisdecemasempresasdirigidaspor Roberto Marinho, segundo publicação recente, num total de vinte mil funcionários. Este homem, que se diz jornal ista e que começou em 1926, quando seu pai, Irineu Marinho, fundou o jornal O Globo, aos 90 anos de idade, integrante da A cademia Brasileira de Letras, é dono de um conjunto de interesses que vão do campo de saúde (com a Golden Cross) ao da própria infra-estrutura da comunicação (como o episódio da NEC, do empresário Mario Garnero), atingindo hoje a televisão por cabo eassim por diante. A Globo também já investiu em emissoras no exterior e atualmenteacançaenormelucratividadecom a venda de seus programas a dezenas de países, deCubaà China, mesmo quegerando problemascomonão-pagamento dochamado direito conexo de imagem, uma das grandes polêmicas atualmente em nosso país.

M uito além do Cidadão Kane, assim, seja em sua versão de vídeo, seja agora na versão que chega ao livro, através do roteiro transcrito, presta ao Brasil esse bom serviço: mais do quefalar da Globo, fala-nos sobreos processos e emaranhados que determinam a política de telecomunicações no Brasil. A Globo, na verdade, é apenas uma conseqüência disso. Se entendermos com clareza tal situação, conseguiremos, quem sabe, nos próximos anos, avançar na solução para esse problema, modificando, passo a passo, a atual legislação. Se isso não ocorrer, de pouco ou nada adiantará o encaminhamento de outros problemas urgentes que o paísenfrenta: continuaremosumanação pela metade e, portanto, também cidadãos pela metade.

\section{Referência Bibliográfica}

MELLO, Geraldo Anhaia. M uito além do cidadão Kane. São Paulo: Scritta Editorial, 1994. 